\title{
Effects of Different Types of Adults' Language Input on Function Word Learning in Children with Language Delays
}

\author{
Bhuja Chung, ${ }^{\mathrm{a}}$, Miri Kim ${ }^{\mathrm{b}}$ \\ a Department of Speech-Language Pathology, Chosun University, Gwangju, Korea \\ ${ }^{b}$ Jun Rehabilitation Clinic, Seoul, Korea
}

Correspondence: Bhuja Chung, $\mathrm{PhD}$

Department of Speech-Language Pathology,

Chosun University, 309 Philmundae-ro, Dong-gu,

Gwangju 61452, Korea

Tel: $+82-62-230-7858$

Fax: +82-62-230-6271

E-mail: bjchung@chosun.ac.kr

Received: April 5, 2020

Revised: May 10, 2020

Accepted: May 11, 2020
Objectives: Although telegraphic utterance is a natural stage of children's language development, there is considerable controversy over the use of telegraphic input to young children, especially those with language delay. Therefore, understanding whether telegraphic input is effective is important because many SLPs reported using the input while feeling it was not useful. The purpose of this study was to determine whether children with language delay are more likely to respond to input in a grammatically complete condition rather than to input in a telegraphic condition. Methods: Subjects in this study were four children between 3 and 4 years of age with developmental language delay. They participated in a single-case alternating treatment design with 3 baseline phase sessions, 12 treatment phase sessions, and 3 maintenance phase sessions. Alternating orders of the 12 sessions in the treatment phase were randomly assigned splitting into grammatical and telegraphic conditions. Children were repetitively given 6 particles and 4 connective endings in natural and various script play contexts using focused stimulation and expansion methods. Results: Children produced significantly more particles when presented with grammatically complete sentences. No differences between conditions in 2 out of 4 children were found for the rates of connective endings. Conclusion: These findings revealed that children who are ready for immediate change would benefit more from grammatically complete prompts whereas those who are less ready would need more support. Overall, children are likely to respond to a grammatically complete input as an intervention technique. Clinical and theoretical implications of the results are discussed.

Keywords: Telegraphic, Grammatically complete, Scripts, Language delay
선행연구들은 아동과 상호작용하는 상황에서 성인이 대상의 인 지 및 이해 수준에 적합하게 자신의 언어 형식을, 아마도 무의식적 으로, 여러 방식으로 변형한다는 결과를 보여주었고 이를 엄마 말 (motherese) 혹은 아동대상 말(child-directed speech)이라고 일컬 었다(Fernald et al., 1989; Grieser \& Kuhl, 1988; Hoff, 2014). 아동 에게 말을 할 때 성인의 음조는 높아지고, 길게 쉬며, 짧은 구를 사 용하는데 유아는 그런 특질에 흥미를 좀 더 보이고 성인스타일의 말투보다 더 선호한다고 한다(Trainor \& Desjardins, 2002). 성인이 영아나 아동에게 사용하는 언어 형식은 모음을 길게 연장하기 때
문에 영아가 뚜렷이 지각할 수 있고(Liu, Kuhl, \& Tsao, 2003), 한 단 어씩 끊어서 들려주는 특성이 있기 때문에 아동이 문장에서 단어 를 분절하기에도 용이하다(Lew-Williams, Pelucchi, \& Saffran, 2011). 다시 말하면 이는 양육자가 분절 없이 길고 복잡한 특징 없 는 문장으로 말한다면 일반아동일지라도 지속적으로 주의를 기울 이거나 주어진 언어 자극 간의 패턴을 찾아내는 통계적 학습을 하 기 어렵다는 의미가 될 수도 있다(Aslin \& Newport, 2012). 때문에 단단어 및 초기 다단어 조합 문장 수준의 언어장애아동을 다루는 연구자와 임상가는 모두 아동의 발화보다 조금 더 확장된 수준의 
단순한 문장을 사용해야 함에 동의한다. 그렇다면 ‘단순한 문장’이 란 어떤 형식이어야하는가?

전보식 문장(telegraphic speech)은 유아기 언어 발달과정에서 자 연스럽게 나타나는 내용어 중심의 초기 다단어 조합 문장 형식을 일컫는다. 전보식 문장은 상대적으로 길이가 짧고, 조사, 어미, 접속 사와 같은 의존형태소는 생략하지만 명사, 동사, 형용사 등의 내용 어는 유지하기 때문에(예: 그네 밀어, 아가 손 아파) 아동뿐 아니라 영유아와상호작용하는 양육자의 발화에서도 자주 관찰되는 문장 형식이다(Brown, 1973; Hoff, 2014). 이런 형식의 문장은 어휘다양 도가 낮고, 처리과정이 복잡하지 않으며, 구어 모방이 용이하여 아 동이 발화의 의미 관계에 주의를 기울이기 쉬우므로 언어장애아동 에게 효율적으로 사용할 수 있는 자극 형식이라고 알려졌다(Van Kleeck et al., 2010 참고). 반면, 비록 전보식 문장이 발달과정에서 나 타나는 자연스러운 언어 형식이라 하더라도 양육자나 임상가가 어 린 아동, 특히 언어에 어려움을 보이는 아동에게 제시하는 언어자 극의 형식으로 적합한가에 관한 논의는 꾸준히 진행되었다(Bredin-Oja \& Fey, 2014; Lorang, Venker, \& Sterling, 2020; Venker et al., 2015). 이 논의는 아마도 아동이 왜 특정 발달 시점에 문법형태 소라는 구조적 기능을 생략한 채 문장을 형성하는가에 관한 설명 과 관련될 수 있을 것이다. Hoff (2014)는 기능어와 굴절어는 그 단 어나 형태소가 전달하고자 하는 문장에서 중요한 의미를 지니지 않 을 뿐만 아니라 아동이 지닌 인지적 제한 때문에 생략되는 경향이 있다고 설명하였다. 문법 지식의 부족이 아니라 인지 상의 제한과 기능적 이유 때문에 덜 중요한 요소를 생략하여 표현하는 경향을 보인다는 설명은 아동이 구어로 표현하기 전부터 상당량의 형태소 혹은 형태소의 문법적 기능을 이미 파악하고 있다는 연구결과에 의해 뒷받침되었다(Eyer et al., 2002; Fernald, \& Hurtado, 2006; Tomasello \& Olguin, 1993). 따라서 기능어나 굴절어가 생략된 발화를 보이는 아동일지라도 이미 문법 요소를 학습하기 위한 잠재력을 지 니고 있을 터이므로 단순하지만 문법 요소가 정확히 포함된 문장 자극을 제시하는 것이 아동의 언어발달 촉진에 효과적일 것이다.

이러한 논의와 관련하여 Bredin-Oja와 Fey (2014)는 5명의 언어 발달지연아동을 대상으로 14 회기에 걸쳐 다른 문장자극 유형의 효 과를 탐색하는 단일대상연구를 실시하였다. 그 결과 전보식 문장 과 문법적으로 완성된 문장 자극이 의미관계 습득에는 서로 차이 를 보이지 않았으나, 문법적으로 완전한 문장자극을 제공하는 경 우 문법형태소의 습득이 유의하게 촉진되었다는 결과를 보고하였 다. Van Kleeck 등(2010) 또한 전보식 언어자극과 문법적으로 완전 한 언어자극에 관한 메타분석을 실시하였고 근거중심중재의 관점 에서 전문가들이 전보식 자극을 사용하는데 부정적이었음을 보고
하였다. Venker, Yasick과 McDaniel (2019)이 실시한 조사결과에서 도 대부분의 언어영역 전문인들이 문법형태소가 생략된 전보식 문 장자극의 효과에 관해 회의적인 견해를 밝혔는데, 흥미로운 부분 은 그럼에도 불구하고 $82 \%$ 이상의 전문인들이 중재상황에서는 여 전히 전보식의 단순한 문장을 사용하는 것으로 나타났다는 점이 었다. 인식과 적용 사이의 이러한 불일치는 중재유형이나 접근법에 관한 합의가 이론과 경험에 기반한 연구자와 현장 전문가의 제언만 이 아니라 다년간의 풍부한 연구결과에 근거해야 하는 것임에도 해 당 주제에 관한 논의가 실험적 증거에 기반하여 활발히 이루어지지 못했음을 반증하고 있다.

더욱이 영어권의 유아기 전보식 발화에는 동사 굴절어, 관사, 전 치사 등이 생략되는 반면, 한국어의 전보식 발화에는 조사나 어미 와 같은 문법형태소의 생략이 두드러지므로(Lee, Chang-Song, Choi, \& Lee, 2008) 한국어의 특성과 발달과정을 고려한 연구가 필 요하다. 국내에서는 Chang-Song, Lim과 Kwak (2004)이 책 읽기 상 황에서 보이는 어머니 말을 품사별로 분류하여 13 개월부터 36 개월 아동의 초기 어휘발달에 미치는 영향을 살펴보았을 때 어머니 말 중 대명사와 관형사의 영향력이 유의하였음을 보고한 바 있다. 그 러나 이 연구들은 어머니의 언어적 입력을 명사와 동사, 관형사 등 의 품사로 한정하였고, 발화 내 기능어 출현 여부에 초점을 맞추거 나 아동의 문법형태소 습득 효과를 탐색한 연구는 아니었다. 그 외 에도 놀이 상호작용 상황에서 전보식 문장이 포함되는 모성어(motherese) 사용 등의 발화촉진행동을 하였을 때 15 개월에서 17 개월 영 아의 의사표현 몸짓과 어휘발달이 유의하게 증가하였음이 확인되 기도 하였다(Song, 2016).

지금까지 살펴본 국내외 선행연구들은 성인이 단순하고 쉬운 언 어를 양적으로 많이 반복할 때보다 질문하기나 피드백 제공 등의 방 식과 함께 상호작용과정에서 질적으로 복잡하고 풍부한 어휘를 단 순한 문장 형식과 함께 제공할 때 높은 수준의 언어발달이 촉진된 다고 설명하였다(Chang, Lee, Kwak, \& Sung, 2003; Weizman \& Snow, 2001). Song (2016)은 전보식 발화 형식의 모성어로 흥미를 끌 고 주의를 전환하는 것 만으로 향상된 수준의 언어발달을 촉진하기 는 어렵다고 설명하면서 '문법이 파괴된 불완전한 형태의 단순하고 쉬운 언어적 자극을 제시하는 것보다 질적으로 완전한 형태의 풍부 하고 체계적인 언어 자극이 영아의 언어발달을 돕는다(p. 11)'고 첨 언하였다. 아동의 언어발달을 촉진하는 '질적으로 복잡하고 풍부한 어휘'에는 명사, 동사, 관형사뿐만 아니라 조사나 어미와 같은 문법 형태소도 포함되어야 하나 지금까지 이러한 문법 요소의 중재에 초 점을 맞추어 자극 형식의 차이를 탐색한 국내 연구는 미비하였다.

위와 같은 논의에 기초하여 본 연구는 학령전기 언어발달지연아 
동을 대상으로 전보식과 문법적으로 완성된 문장 형식의 두 가지 언어 자극 유형이 기능어 표현에 유의한 차별적 영향을 미치는지 탐색하고자 하였다. 다시 말해 본 연구의 목적은 문법적으로 완전 한 문장을 통해 자연스럽게 제시되는 다양한 문법형태소 자극이 아동으로 하여금 해당 문법 요소를 사용하도록 촉진하는지 파악 하는데 있었다. 이를 위해 인지적 처리가 용이하고, 새로운 단어나 문장의 습득을 자연스럽게 촉진할 수 있는 스크립트 맥락을 활용 하였으며, 소수의 아동에게 여러 중재를 단기간에 교환하여 실시함 으로써 중재들 간의 효과를 비교할 수 있는 교대중재설계(alternating treatment design, ATD) 단일대상연구 방식을 적용하였다.

\section{연구방법}

\section{연구대상 및 특성}

본 연구는 조선대학교 기관생명윤리위원회(IRB, 2-1041055-AB$\mathrm{N}-01-2016-0015)$ 의 승인을 얻은 후 대상아동의 양육자에게 실험 절차와 과정에 대한 동의를 받아 진행하였다. 본 연구의 대상 아동 은 생활연령 3,4 세의 언어발달지연아동 4 명으로 공통적인 조건은 다음과 같았다. (1) 주 양육자로부터 신체, 운동, 감각, 정서 등의 영 역에서 발달상의 결함이 보고되지 않았으며, (2) 한국판 라이터 비 언어성 지능검사(K-Leiter-R; Shin \& Cho, 2012) 결과 비언어 지능 이 80 점 이상으로 정상 범주에 해당하고, (3) 취학 전 아동의 수용 언어 및 표현언어 발달척도(PRES; Kim, Seong, \& Lee, 2003) 결과 수용 또는 표현 언어의 백분위수가 10 미만에 속하거나 통합언어 발달연령이 생활연령 대비 1 년 이상 지연을 보이는 아동이다. 또한 (4) 스크립트 활동을 이용한 자유놀이 상황에서 자발화를 수집하 여 분석하였을 때 평균 어절 길이(Mean Length of Utterance in clutters, MLU-c; Kim, 2016 참고)가 아동에 따라 1.4에서 2.0사이 에 해당하여 구문표현 상에서 또래보다 지연을 보인 경우로 선정하 였다. 이는 대상자의 연령을 기준으로 하였을 때 $-2 \mathrm{SD}$ 에 속하는 수 준이기 때문이다(Kim, 2014). 해당 아동들은 모두 (5) 언어치료를 받은 경험이 없는 아동으로 선정하였으며, 연구가 진행되는 기간에 언어치료를 시작하지 않음을 전제조건으로 하였다.

위 공통적인 조건에 부합하여 최종적으로 선정된 연구대상 아 동 4명의 생활연령, 비언어 지능, 언어 수준, MLU-c는 Table 1 에 제 시된 바와같다.

아동 별로 언어 특성을 살펴보면, P1 아동은 자발적으로 대화를 시작하지 않았으며 놀이상황에서 주로 두 단어 조합문장을 사용 하여 대답하였고 세 단어 조합문장은 거의 보이지 않았다. 아동은 '이거’ 대용어를 사용한 문장과 의문사질문(예: "이거는 올리고”, “이
Table 1. Pre-experiment participant's characteristics

\begin{tabular}{llcclc}
\hline Participant & Sex & Age & K-Leiter-R & \multicolumn{1}{c}{ PRES (\%ile) } & MLU-c \\
\hline P1 & Male & $3 ; 1$ & 100 & R: 4\%ile, E: 13\%ile & 1.9 \\
P2 & Female & $4 ; 3$ & 87 & R: 44\%ile, E: 8\%ile & 1.8 \\
P3 & Male & $3 ; 3$ & 93 & R: 3\%ile, E: $2 \%$ ile & 1.9 \\
P4 & female & $4 ; 0$ & 93 & R: 8\%ile, E: under 1\%ile & 1.7 \\
\hline
\end{tabular}

All reported sores are raw scores except for Nonverbal I0 scores. PRES=Preschool Receptive-Expressive Language Scale (Kim et al., 2003); $R=$ Receptive; $\mathrm{E}=$ Expressive; MLU- $\mathrm{c}=$ Mean Length of Utterance in Clutters.

거 꽂을까?”)을 자주 사용하였으며, '이거는?'과 같은 질문으로 상대 방이 사물의 이름을 말해주기를 계속 요청하였다. 기능어로는 주격 조사 ‘-는, 공존격조사'-랑', 연결어미 '-는데'를 표현할수 있었다.

$\mathrm{P} 2$ 아동은 놀이상황에서 한 단어와 두 단어 조합문장을 사용해 서 자주 설명하였고 간혹 세 단어 조합문장도 표현하였다. 자신의 이름을 넣어 "00 꺼", "00 숟가락 줘” 등으로 말하였으며, 대용어 ‘이거'의 사용도 빈번하였다. 기능어로는 주격조사 과잉일반화가 자 주 나타났고(예: “선생님이가 써”) 공존격조사 ‘-랑’과 보조격조사 ‘-이/가'를 사용하기 시작하였다. 연결어미 '-는데’ 또한 관찰되었다.

P3 아동은 한 단어와 두 단어 조합문장을 주로 사용하였으며 세 단어 조합문장도 말할 수 있었다. 놀이 상황에서 행동요구가 빈번 하였으며(예: “불 주세요”, “여기 내려놔요”, "계속 봐봐요”), 격조사 의 오류가 자주 나타났다(예: "마트에가 있어요", "숟가락이 가져와 요”, “초코가 줘야지요”). 자발화에서 주격조사 ‘-이/가', 공존격조 사 ‘랑', 보격조사 ‘-이/가', 보조사 ‘-만' 등의 여러 조사를 사용하였 으나 연결어미 사용은 관찰되지 않았다.

P4 아동은 주로 한 단어에서 두 단어 조합문장을 사용하였으며, 세 단어 조합문장 표현은 매우 드물었다. 놀이상황에서 일어나는 내용을 빈번히 언급하였으며(예: “뽀로로 잡았지”, “케이크 있어”, “사진기 있네”), 기능어 측면에서 연결어미 '-는데'는 자주 출현한 반면 주격조사'-는'과 보격조사 '-이’만을 간혹 사용하였다.

\section{연구 내용 및 활동}

\section{자극 제시 조건 및 방법}

본 연구에서는 성인의 언어자극 제시 유형에 따라 전보식 언어촉 진활동(telegraphic Input, TI) 조건과 문법완성식 언어촉진활동 (grammatically complete input, GI) 조건으로 나누어 중재를 실시 하였다. TI 조건에서는 연구자가 아동에게 조사, 연결어미 등의 기 능어를 생략한 문장을 제공하고, GI 조건에서는 기능어가 모두 포 함되어 문법적으로 완전한 문장을 제공하였다. 본 연구의 GI 조건 에서 중재 단계 동안 제공할 기능어는 격조사, 보조사, 연결어미로 제한하였다. 
중재단계에서 자극을 제시하는 문장형식으로는 $\operatorname{Kim}(2014)$ 이 제시한 의미관계 유형의 평균 출현 순위를 근거로 기능어를 제공하 기 위한 실체-서술, 대상-행위, 배경-행위, 행위자-행위의 두 단어 의 미관계와 실체-배경-서술, 대상-배경-행위, 행위자-대상-행위, 행위 자-배경-행위의 세 단어 의미관계를 선정하였다.

두 가지 촉진활동 조건에서 모두 아동의 모방반응을 요구하지 않는 집중적인 자극법(focused stimulation)과 간접적인 구어적 단 서를 사용하였다. TI조건에서는 아동의 말을 연구자가 그대로 모 방함으로써 아동에게 자신의 말이 전달되었음을 알리거나, 기능어 가 생략된 문장으로 집중적인 언어자극을 제공하였다. GI 조건에 서는 아동의 문장구조를 유지한 채 본 연구에서 목표한 기능어(조 사 및 연결어미)를 첨가한 구문 확장 전략을 적용하였다. 일례로, 미술놀이 스크립트 활동을 진행하는 동안 연구자가 제공하는 TI 조건의 자극은 '별 색칠해요', '선생님 기차 꺼내요'와 같으며, GI 조 건의 자극은 '별도 색칠해요' '선생님이 기차를 꺼내요'와 같이 목표 한 기능어를 포함하는 문장이다.

\section{기능어 유형}

선행연구에 의하면 2세부터 주격조사가, 3-4세부터는 처소격, 목 적격, 도구격 조사가(Pae, 1997; Yi, 2000) 빈번히 출현한다. 따라서 본 연구에서는 가장 이른 시기에 나타나는 주격조사를 제외하고 3 세 경 사용이 보고되는 처소격 '-에/에서', 목적격 '-을/를', 도구격 '-로'(Kwon \& Lee, 1999), 보조사 ‘-도'(Kwon \& Jung, 1999; Yi, 2000) 의 총 여섯 개 조사를 제공될 기능어로 선정하였다. 연결어미에서 도 마찬가지로 3세 경부터 나타나는 것으로 보고되는 나열 '-고', 이 유/원인 '-아/어서', 조건 '-면'의 총 네 개 연결어미를 기능어로 선정 하였다(Chung, 2013).

\section{중재활동}

본 연구에서는 대상아동에게 동일한 활동 맥락을 제공하기 위 해 미술 놀이, 옷 입고 놀이터 가기, 마트 놀이의 3 가지 스크립트 활 동(각 20 분)을 구성하였다. 스크립트는 일상적이고 친숙한 사건에 서 상황 지식을 공유하며 하위 사건을 인지적으로 연결함으로써 인과관계 추론이 용이하기 때문에 두세 단어 의미관계 문장 수준 아동을 위한 중재활동으로 적합하다(Kim \& Lombardino, 1991). 본 연구에서는 총 12 번의 중재 회기 동안 3 가지 스크립트 활동을 4 회씩 되풀이함으로써 언어발달지연아동의 인지 및 언어적 부하 를 줄이고 목표한 기능어를 반복적으로 제시할 수 있도록 구성하 였다. 중재활동에서 사용하는 스크립트 활동의 종류와 도구, 상세 한 활동의 예는 Appendix 1과2에 제시하였다.

\section{연구설계 및 절차}

연구설계

본 연구에서는 4 명의 아동을 대상으로 TI 조건과 GI 조건에서 나타나는 기능어의 산출 비율을 비교하여 어떤 언어촉진자극이 아동의 기능어 표현에 긍정적인 영향을 미치는 지 탐색하기 위해 교대중재설계(alternating treatments design, ATD)를 적용하였다. 본 연구에서 독립변인은 TI과 GI이며 종속변인은 기능어의 산출 비율이었다. 모든 중재는 아동이 속한 교육기관이나 가정의 독립되 고 조용한 장소에서 개별적으로 실시하였으며, 대상 아동과 연구자 의 대화 및 상호작용이 잘 관찰될 수 있는 곳에 캠코더(소니 HDR$\mathrm{AZ1)}$ 를 설치하고 모든 과정을 비디오로 녹화한 후 전사하였다.

\section{연구절차}

중재절차는 기초선, 중재, 유지 회기의 순으로 진행되었으며, 각 단계의 내용은 다음과 같다.

\section{기초선 단계}

기초선 단계는 독립변인이 주어지기 전 목표한 기능어 및 관련 자료를 수집하는 기간을 의미하였다. 본 연구의 기초선 단계에서는 스크립트 활동을 적용한 자유 놀이 상황에서 3 회기 동안 20 분씩 실시한 후 아동 별로 자발화에서 보인 기능어의 산출비율과 MLU-c 를 측정하였다. 이때 스크립트 활동은 중재 단계에서 진행되지 않 는 활동(생일파티 놀이)으로 선정하였다. 이 기간에는 독립변인과 관련된 구어 자극을 적용하지 않았으며, 사전 예비연구를 통해 작 성한 분석표를 바탕으로 분석한 기능어 산출 비율을 그래프로 제 시하여 안정화 여부를 확인하였다.

\section{중재 단계}

중재 단계는 기초선이 3 회 이상 안정되었을 때 각 아동을 대상으 로 회기당 주 3 회씩 2 주 동안 총 12 회기의 활동으로 진행되었으며, 매 회기는 20 분 간 지속되었다. 매 중재 회기 후 동영상 전사 및 분 석을 진행하여 아동의 수행을 분석하였다. 중재활동은 3 가지 스크 립트 활동과 2 가지의 언어촉진 활동 조건을 짝 지은 후 이를 2 회씩 반복하여 총 12 회기로 진행하였다 $(3 \times 2 \times 2)$. 동일한 스크립트 활 동을 반복하는 이유는 어휘의 다양성을 통제하고, 미리 선정한 기 능어를 효과적으로 제공하기 위함이었다. 반면 교대중재설계의 순 서효과와 이월효과(carryover effect)를 통제하기 위해 중재 회기의 순서를 무작위로 배열하였으며, 연습효과를 통제하기 위해 연속으 로 동일한 스크립트 활동이 진행되지 않도록 조절하였다. 중재 단 계에서 매 회기 스크립트 활동이 다르게 배치되어 성인이 제시하는 
어휘가 달라지므로 이월효과를 통제하는 결과를 얻을 수 있었다. 배열된 중재 회기의 순서는 Table 2와 같으며, 각 대상아동에게 동 일하게 적용되었다. 중재의 종결은 TI 조건 6회기, GI 조건 6회기 총 12 회기가 되는 시점으로 정하였다.

\section{유지 단계}

유지 단계는 GI 조건의 결과 아동의 기능성 표현 비율이 잘 유지 되고 있는지 알아보기 위해, 중재가 종결된 지 2주 후에 기초선과 동일한 생일파티 놀이상황에서 실시하였고 동일한 평가기준을 적 용하여 발화를 분석하였다.

\section{분석 기준 및 방법}

발화를 분석하는 기준은 기능어 산출비율로서 아동의 발화를 전 사한 후 해당 조건 내 전체 발화에서 목표한 기능어가 산출된 빈도 를 토대로 산출하였다. 즉, 매 회기마다 아동이 표현한 각 기능어의 총수를 해당 회기 전체 발화수로 나눈 후 100 을 곱한 방식이었다.

\section{신뢰도}

$\mathrm{ATD}$ 에서는 연구자의 일관된 중재, 즉 독립변인의 신뢰도가 주 요 변수이기에(Lee, Park, \& Kim, 2000), 본 연구에서는 중재의 준 비 및 중재과정의 적절성, 충실성 등을 객관적으로 평가하여 연구 의 타당도를 높이고자 중재충실도를 검증하였다. 먼저 언어치료경 력 3 년 이상의 언어치료 전공자이자 2 급 언어재활사 자격증 소지자 인 평가자 1 인과 연구자가 전체 중재 회기 중 $25 \%$ 에 해당하는 영상 자료를 무작위로 선정하여 살펴본 후 미리 작성한 중재충실도 체 크리스트의 각 문항에 대해 5점 척도로 평가를 하였다. 해당 체크 리스트는 '연구자가 스크립트 내용에 충실하게 중재하였는가?', ‘스

Table 2. Experimental procedures of scripts and conditions throughout sessions

\begin{tabular}{clc}
\hline Session & \multicolumn{1}{c}{ Scripts in conditions } & Repetition order \\
\hline 1 & Art play in Tl condition & 1 st \\
2 & Shopping play in Tl condition & $1 s t$ \\
3 & Dressing and playground play in Gl condition & 1 st \\
4 & Shopping play in Tl condition & $2 \mathrm{nd}$ \\
5 & Art Play in Gl condition & $1 \mathrm{st}$ \\
6 & Dressing and playground play in TI condition & $1 \mathrm{st}$ \\
7 & Shopping play in Gl condition & $1 \mathrm{st}$ \\
8 & Art Play in Gl condition & $2 \mathrm{nd}$ \\
9 & Dressing and playground play in TI condition & $2 \mathrm{nd}$ \\
10 & Art Play in Tl condition & $2 \mathrm{nd}$ \\
11 & Shopping play in Gl condition & $2 \mathrm{nd}$ \\
12 & Dressing and playground play in Gl condition & 2nd \\
\hline
\end{tabular}

크립트 과제가 아동의 수준에 적절한가?', '아동의 반응에 적절한 집중적인 자극과 간접적인 구어가 제시되었는가?' 등의 문항으로 구성되어 있다. 그 결과 4 명의 아동에 걸쳐 91.4-98.1의 중재충실도 평균점수를 얻을 수 있었다.

또한 종속변인의 신뢰도를 검증하기 위해 먼저 위 평가자 1 인과 연구자가 자료를 전사하고, 분석하는 사전연습을 진행하여 일치도 가 $95 \%$ 이상이 되도록 연습하였다. 그 후 전체 중재 회기의 $25 \%$ 에 해당하는 아동의 발화와 기능어 산출 비율을 각자 분석하였고, 그 결과 아동에 걸쳐 88.3-100에 이르는 조사 및 연결어미 분석 일치 도를 얻을 수 있었다.

\section{연구결과}

\section{언어촉진방법에 따른 조사 표현 비율}

본 연구에서 $\mathrm{TI}$ 조건과 $\mathrm{GI}$ 조건 중 어떤 조건에서 진행한 촉진 활동 이 언어발달지연아동의 조사 표현에 긍정적인 영향을 미치는지 알아 보기 위해, 기초선 단계 3 회기, 중재 단계 12회기(TI 6회기, GI 6회기), 유지 단계 3회기 동안 매 회 표현된 여섯 개 조사의 비율을 계산하여 비교분석하였다. 각아동이 보인 단계 별 조사표현 비율의 평균 및 범 위는 Table 3에 제시하였으며, 그추세는 Figure 1에 제시된 바와같다.

$\mathrm{P} 1$ 이 기초선 단계 동안 보인 평균 조사 표현 비율은 $4.72 \%$ 로 3 회 에 걸쳐 안정적인 경향을 나타냈다. 중재 단계 동안 $\mathrm{TI}$ 조건에서는 평균 $6.54 \%, \mathrm{GI}$ 조건에서는 평균 $7.55 \%$ 의 조사 표현 비율을 보였으 며, 유지 단계에서는 평균 $11.87 \%$ 조사 표현 비율을 보여 기초선 기 간보다 증가한 유지율을 보였다. P2의 경우 기초선 단계 동안 조사 표현 비율은 평균 $3.55 \%$ 로 저조한 편에 속하였다. 그러나 중재 회기 가 진행되면서 TI 조건에서는 평균 5.40\%의 비율을 보인 반면, GI 조건에서 $11.12 \%$ 의 평균 조사 표현 비율을 보였으며, 유지 단계에 서도 평균 $9.19 \%$ 의 비율로 기초선 단계보다 높은 유지율을 나타냈 다. P3은 기초선 단계 동안 평균 $5.89 \%$ 의 조사 표현 비율을 보였으 며, 중재 단계에서는 TI 6.70\%, GI 11.60\%으로 GI 조건에서 전반적

Table 3. Mean and range of production rate in particles in TI and GI conditions (\%)

\begin{tabular}{lccrc}
\hline \multirow{2}{*}{ Participant } & \multirow{2}{*}{$\begin{array}{c}\text { Baseline } \\
\text { phase }\end{array}$} & \multicolumn{2}{c}{ Intervention phase } & \multirow{2}{*}{$\begin{array}{c}\text { Maintenance } \\
\text { phase }\end{array}$} \\
\cline { 3 - 4 } & & \multicolumn{1}{c}{$\mathrm{TI}$} & $\mathrm{Gl}$ & \\
\hline P1 & $4.72(4-7)$ & $6.54(3-11)$ & $7.55(4-12)$ & $11.87(10-13)$ \\
P2 & $3.55(3-5)$ & $5.40(2-14)$ & $11.12(4-24)$ & $9.19(8-10)$ \\
P3 & $5.89(6-8)$ & $6.70(3-12)$ & $11.60(8-15)$ & $6.85(5-8)$ \\
P4 & $2.92(1-4)$ & $5.63(1-9)$ & $6.64(4-11)$ & $5.82(4-7)$ \\
\hline
\end{tabular}

Values are presented as percentage (range). 

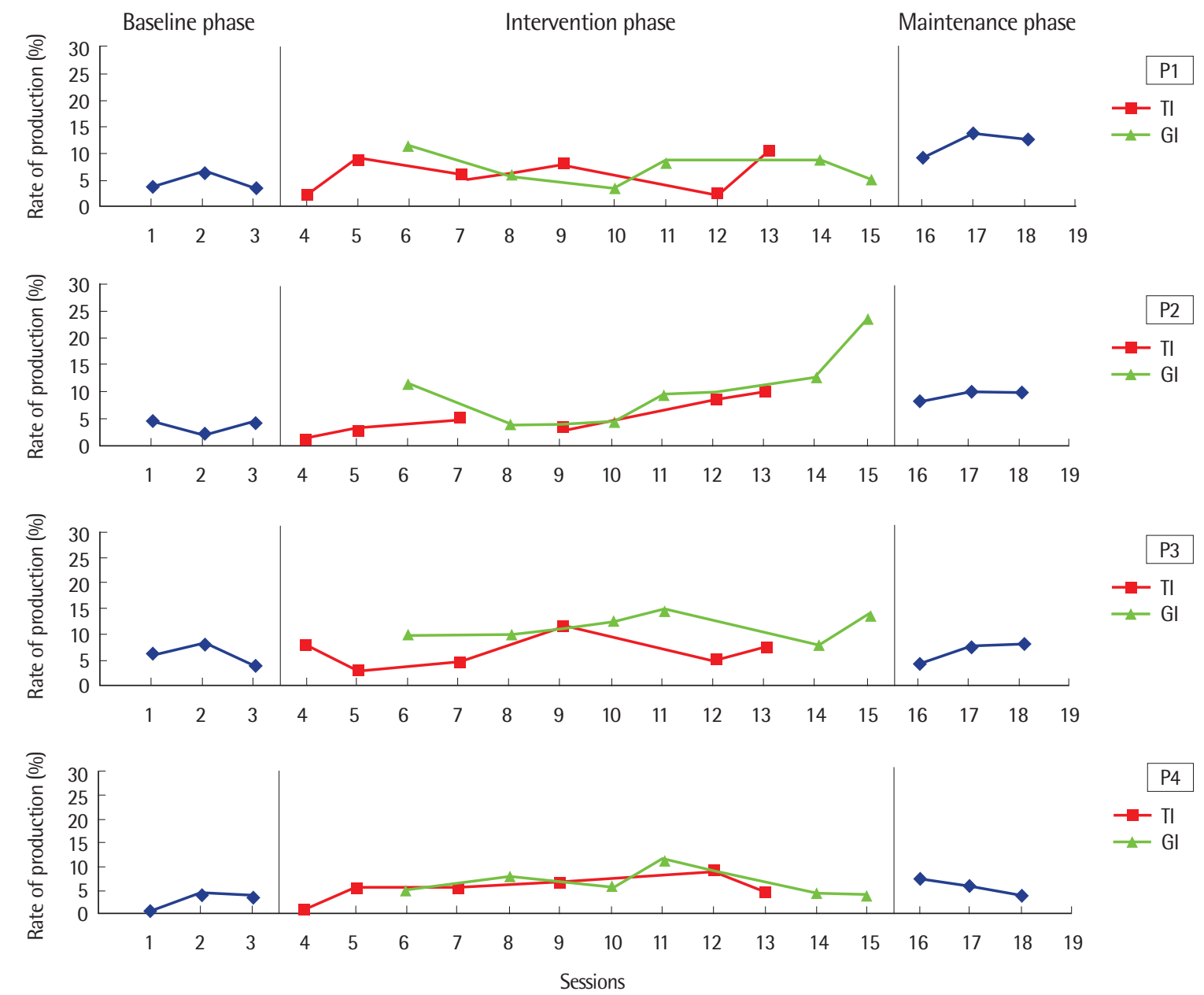

Figure 1. Rate of production in particles.

$\mathrm{TI}=$ Input in telegraphic condition; GI = Input in grammatical condition .

으로 높은 조사 표현 비율을 유지하는 것으로 나타났다. 유지 단계 에서도 평균 $6.85 \%$ 로 기초선이나 TI 조건과 비교해서도 높은 수준 으로 조사 표현을 유지하는 것으로 분석되었다. 반면 P4는 기초선 단계의 조사 표현 비율이 $2.92 \%$ 로 낮았고, 중재 단계에서 TI $5.63 \%$, GI 6.64\%로 그 차이가 다른 아동에 비해 크지 않았다. 유지 단계에 서는 $5.82 \%$ 의 조사 표현 비율을 보여 기초선 단계 및 TI 조건보다 다소 높은 유지율을 지속하였다.

위의 결과를 종합하면 P1, P2, P3의 경우 중재 단계의 초기 TI 조 건에 비해 GI 조건에서 문장과 함께 조사를 제공하기 시작하자 아 동의 조사 표현 비율의 증가를 보이기 시작하였다. P2와 P3에게서 는 회기가 지속되면서 뚜렷한 조사 표현 비율의 상승을 관찰할 수 있었다. 비록 중재 회기 단계에서 P1과 P4가 지속적인 증가율을 보 이지는 않았으나 2 주 후 유지 단계에서 관찰한 조사 표현의 비율은 기초선 단계에 비해 더 증가한 것으로 분석되었다.
조사 별로 살펴보면 P1은 기초선 단계에서는 낮은 빈도로 사용 했던 '-로'와 '-도'가 중재 단계와 유지 단계에서 높은 빈도로 출현하 였다. 반면 '-을/를'은 기초선, 중재 및 유지 단계에서 사용이 확인되 지 않았다. P2는 기초선 단계에서 드물게 사용하였던 모든 목표 조 사의 빈도가 GI 조건에서 뚜렷이 증가하였으며, 유지 단계에서도 높은 빈도로 사용하였다. 또한 유지 단계에서 목표하지 않았던 보 조사 '만' '-은/는'도 추가로 나타났다. P3과 P4의 경우 기초선 단계 에서 자주 사용하던 조사인 '-에'와 '-도'는 GI 조건에서 그 사용빈 도가 증가하였고, 기초선 단계에서 사용빈도가 매우 낮았던 '-을/ 를'과 '-로'는 GI와 TI 조건 모두에서 여전히 사용하지 않거나 조건 간에 큰 차이를 보이지 않았다.

\section{언어촉진방법에 따른 연결어미 표현 비율}

본 연구에서 $\mathrm{TI}$ 조건과 GI 조건 중 어떤 조건의 촉진 활동이 언어 
발달지연아동의 연결어미 표현에 긍정적인 영향을 미치는지 알아 보기 위해, 기초선 단계 3회기, 중재 단계 12회기(TI 6회기, GI 6회 기), 유지 단계 3 회기 동안 매 회 표현된 네 개 연결어미의 비율을 계 산하여 비교 분석하였다. 각 아동이 보인 연결어미 표현 비율의 평 균 및 범위는 Table 4에, 그 추세는 Figure 2에 제시된 바와 같다.

Table 4. Mean and range of production rate in connective ending in $\mathrm{Tl}$ and $\mathrm{Gl}$ conditions (\%)

\begin{tabular}{lcccc}
\hline \multirow{2}{*}{ Participant } & \multirow{2}{*}{$\begin{array}{c}\text { Baseline } \\
\text { phase }\end{array}$} & \multicolumn{2}{c}{ Intervention phase } & Maintenance \\
\cline { 3 - 4 } & & $\mathrm{TI}$ & $\mathrm{Gl}$ & \\
\hline P1 & $3.27(2-4)$ & $0.97(0-3)$ & $2.19(0-6)$ & $6.75(6-8)$ \\
P2 & $0.37(0-1)$ & $2.33(0-5)$ & $3.58(2-5)$ & $2.47(2-3)$ \\
P3 & $5.98(4-9)$ & $2.68(0-5)$ & $5.89(3-9)$ & $7.56(7-9)$ \\
P4 & $3.37(2-4)$ & $1.97(0-4)$ & $5.02(0-8)$ & $3.09(2-5)$ \\
\hline
\end{tabular}

Values are presented as percentage (range).
$\mathrm{P} 1$ 의 경우 기초선 단계 동안 연결어미의 표현 비율은 평균 $3.27 \%$ 였는데 이때 아동은 연결어미 '-고'만을 빈번히 산출하였다. 중재가 시작된 후 TI 조건에서는 평균 $0.97 \%$, GI 조건에서는 평균 $2.19 \%$ 로 다소 차이를 보였으나 유의하게 분석되지는 않았다. 반면 유지 단 계에서는 $6.75 \%$ 의 연결어미 표현 비율을 보여 조사 표현 비율의 경 향과 유사하게 유지 단계에서 높은 증가율을 보이는 것으로 나타 났다. P2는 기초선 단계 동안 평균 $0.37 \%$ 로 연결어미 표현을 거의 보이지 않았다. 중재 회기 동안 TI 조건 초기에는 나타나지 않던 연 결어미가 GI 조건에서부터 관찰되기 시작하였다. 평균 연결어미 표 현 비율은 TI $2.33 \%$, GI $3.58 \%$ 로 전반적으로 GI 조건에서 연결어 미 표현 비율을 좀 더 보였으며, 유지 단계에서는 평균 $2.47 \%$ 로 기 초선에 비해 높아진 연결어미 비율을 꾸준히 보이는 것으로 분석되 었다. P3이 기초선 단계 동안 보인 연결어미 표현 비율은 P1과 P2에 비해 높아 평균 $5.98 \%$ 를 나타냈다. 중재 단계에서는 TI 조건에서
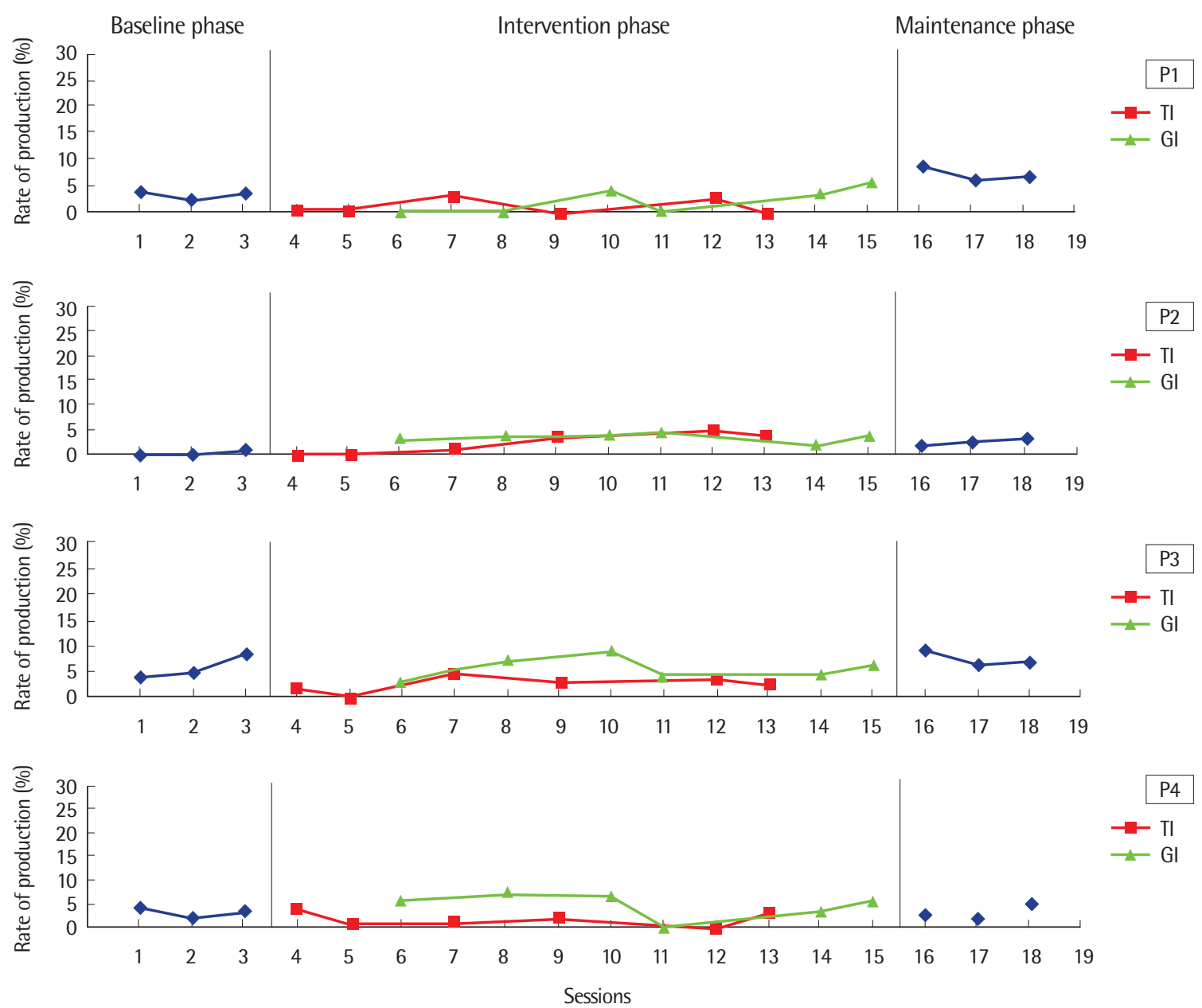

Figure 2. Rate of production in connective endings.

$\mathrm{TI}=$ Input in telegraphic condition; $\mathrm{Gl}$ = Input in grammatical condition . 
$2.68 \%, \mathrm{GI}$ 조건에서 $5.89 \%$ 를 보였고, 유지 단계에서는 $7.56 \%$ 의 높 은 표현비율을 보였다. $\mathrm{P} 4$ 의 경우 기초선 단계 동안 $3.37 \%$ 의 연결어 미 표현 비율이 안정적으로 나타났으며, 중재 회기 동안 TI 조건에 서는 $1.97 \%, \mathrm{GI}$ 조건에서는 $5.02 \%$ 의 연결어미 표현 비율을 보였다. 그러나 유지 단계에서는 평균 $3.09 \%$ 의 비율로 연결어미를 표현하 여 기초선 단계와 유사한 것으로 나타났다.

Figure 1과 연결어미 표현 비율을 종합하였을 때, $\mathrm{P} 4$ 를 제외한 나 머지 아동은 기초선 단계와 유지 단계에서 증가한 연결어미 표현을 보이는 것으로 분석되었다. 반면 중재 회기가 진행되는 동안에는 $\mathrm{P} 3$ 을 제외한 다른 아동들에게서 두 조건 간의 차이는 크게 나타나 지 않았고, P4의 경우 GI 조건에서 더 높은 연결어미 표현 비율을 발견할 수 있었다.

연결어미 별로 살펴보면, $\mathrm{P} 1$ 은 기초선 단계에서 연결어미 '-고'만 을 높은 비율로 사용하였으나, 중재 단계 GI 조건에서 제시한 목표 연결어미가 고르게 나타났다. 특히 중재 후반기에 다양한 연결어미 유형의 산출빈도가 증가하였고 유지 단계까지 지속되었다. P2의 경 우 기초선 단계에서 연결어미 사용 빈도가 매우 낮았으며, 중재 단 계에서도 '-고', '-서' 등이 새롭게 나타났으나 그 빈도는 높지 않았 다. 반면 '-면'은 TI 조건보다 GI 조건에서 더 빈번하였고 유지 단계 에서도 계속 사용이 되었다. P3과 P4는 기초선 단계에서 목표 연결 어미가 모두 출현하였으며, GI 조건에서 산출 빈도가 증가하였다. 두 아동은 기초선 단계에서 P3은 '-면', P4는 '-고'의 사용 빈도가 높 아 평균 비율이 높아졌으나, 중재 및 유지 단계에서는 GI 조건에서 나머지 연결어미의 사용 빈도가 증가하였다

\section{논의 및 결론}

본 연구는 전보식 및 문법완성식의 두 가지 언어자극 유형이 언 어발달지연아동의 기능어(조사와 연결어미) 습득에 어떠한 영향 을 미치는지 탐색하는데 그 목적이 있었다. 이를 위해 학령전기 언 어발달지연아동 4 명을 대상으로 교대중재설계를 적용하여 기초선 단계, 중재 단계, 유지 단계를 거치며 조사 및 연결어미 표현 비율에 서 보이는 추이를 두 자극 유형 조건별로 살펴보았다.

먼저, 전보식 문장을 제공한 조건에 비해 문법적으로 완전한 문 장으로 조사를 제시한 조건에서 전반적으로 높은 조사 표현의 비 율이 보인 것으로 확인되었다. 본 연구와 비슷한 연령대인 30개월에 서 51개월의 표현언어지연아동을 대상으로 한 Bredin-Oja와 Fey (2014)도 유사한 결과를 보고한 바 있었다. 이 연구는 의미관계와 문법형태소를 모두 종속변인으로 하여 즉각적인 모방을 유도하는 방식으로 두 조건을 비교하였는데, 의미관계보다는 문법적 요소를
모방하는 조건에서 뚜렷한 차이가 있었다. 이에 비해 덜 구조적이 고 더 자연스러운 스크립트 상황에서 아동의 발화를 유도한 본 연 구에서도 $\mathrm{GI}$ 조건에서 조사 표현 비율이 증가했다는 것은 전보식 언어촉진방식에 비해 문법적으로 완전하고 단순한 문장을 제시하 는 방식이 조사 표현 촉진에 좀 더 효과적임을 지지하는 결과이다. 본 연구에서는 언어자극조건을 제외한 성인언어의 기타 의미관계 수준, 어휘의 내용, 그리고 놀이 스크립트 상황을 모두 유사하게 적 용하도록 중재환경을 구조화하였다. 또한 Bredin-Oja와 Fey (2014) 의 실험방식과 달리 아동에게 모방을 요구하지 않는 간접적 언어자 극 전략을 활용하였으므로 부모-아동 간에 발생하는 자연스러운 상호작용 상황이나 아동중심 중재상황에도 연구결과를 적용할 수 있을 것이다.

중재 단계에서 언어자극조건에 따라 나타난 조사 표현 비율의 추 이를 살펴보면 특히 P2와 P3아동에게서 증가 폭이 두드러짐을 알 수 있었다. 두 아동이 보인 조사의 다양성 측면에서도 다른 아동에 비해 주격조사 외에 공존격, 보격조사와 보조사를 다양하게 활용 하였으며 해당 조사의 표현이 잘 유지되었다. 반면, $\mathrm{P} 1$ 의 경우 유지 단계에서 높은 조사 표현 비율을 보였으나 조사의 다양성이 부족 하며 동일한 조사를 반복적으로 적용한 것으로 분석되었다. 이러 한 차이는 자연스러운 중재만으로도 조사를 새로 습득하거나, 습 득한 조사를 다양하게 적용하는 학습잠재력의 크기가 아동에 따 라 다르기 때문일 것이다(Bain \& Olswang, 1995).

본 연구에서는 중재 단계를 시작하기에 앞서 기능어를 습득하기 위한 아동의 준비도(학습잠재력)를 확인하기 위해 MLU를 분석하 였다. 이는 기능어 습득을 위한 전제조건이 '구문의 길이'라고 판단 하였기 때문이다. 그러나 연구결과 자극유형에 따라 중재 및 유지 단계에서 다양하고 많은 조사를 습득하고 활용하는 정도에 아동 별로 차이가 나타났고, 이 차이는 중재 이전에 아동이 이미 사용하 였던 조사의 유형이나 빈도와 좀 더 관련이 있는 듯하였다. 즉, 기초 선 단계에서 P1과 P4와 달리 P2와 P3은 빈도는 낮았지만 다양한 유형의 조사를 부정확하더라도 표현하기 시작하였기 때문에 문법 적으로 완성된 문장 속에서 기능어를 자연스럽게 제시하는 상황 이 긍정적인 영향을 준 것으로 해석되었다. Brain과 Olswang (1995) 역시 역동적 평가의 타당성에 관한 연구에서 중재에 대한 학습잠재 력이 높은 아동은 동일한 단서에도 더 큰 폭의 변화를 보인다고 설 명한 바 있어 본 연구의 결과는 이러한 관점에서 지속적으로 탐색 되어야 할 영역으로 사료되었다.

다음으로, 언어촉진조건에 따른 연결어미 표현 비율에 관한 분 석결과 $\mathrm{P} 3$ 을 제외한 나머지 아동에게서 전보식 및 문법완성식 촉 진방법에 따른 차이가 두드러지지는 않았다. 선행연구는 연결어미 
의 습득연령이 조사에 비해 다소 느리고(Chung, 2013), 언어발달이 지연된 아동의 경우 나열 연결어미 '-고'를 제외한 나머지 연결어미 사용 빈도가 매우 낮았다고 보고하였다(Hwang, 2003). 앞서 설명 하였듯 본 연구의 대상 아동은 모두 MLU-c 1.7에서 1.9로 단단어 수준의 표현이 주를 이루거나, 두 세 단어 조합 수준의 문장이 출현 하기 시작하는 3 세 1 개월에서 4 세 3 개월의 언어발달이 지연된 아동 이었다. 더욱이 P1, P3, P4아동은 유지 단계에서 나열형 연결어미 '-고' 혹은 조건형 연결어미 '면'을 반복 사용하여(예: '신발 신고, 모 자 입고, 의자 있고', '먹으면 안돼요. 먹으면 배 아파요. 불 먹으면'), 중재 단계와 유지 단계에서 증가 비율을 보였음에도 Figure 2의 추 이에서 그 차이가 변별력있게 나타나지 않았다. 연결어미별로 살펴 보았을 때 P3과 P4는 기존에 사용하던 연결어미를 GI 조건에서 좀 더 높은 빈도로 활용하는 모습을 보여 조사의 경우와 마찬가지로 자극 유형의 효과는 중재 전에 사용하였던 문법형태소의 빈도를 높 이는 데 더 긍정적으로 작용한다는 해석이 가능하였다. 결과적으 로 본 연구대상 아동의 대부분이 연결어미 촉진문장에 큰 폭의 증 진을 보이지 않았으나, 각 연결어미별 사용 빈도를 고려하였을 때는 문법완성식 문장을 제시하는 조건이 전보식 언어촉진조건에 비해 연결어미를 습득하고 표현하는데 효과적이었다고 파악되었다.

본 연구결과는 기능어의 종류에 따라, 그리고 아동이 기존에 습 득한 기능어의 유형과 빈도에서 나타나는 아동의 학습잠재력에 따 라 표현 비율의 증감에 차이가 있었음을 보여주었다. 또한 언어를 촉진하는 자극이 정확한 문법요소를 포함할수록 제시된 기능어뿐 만 아니라 새로운 기능어의 표현도 촉진하는 것으로 나타났다. Venker와 Stronach (2017)은 문법적으로 완성된 문장자극이 아동 으로 하여금 뒤이을 단어를 예측하도록 도움으로써 언어처리를 촉 진하고, 새로운 단어 학습을 위한 단서를 제공한다고 설명한 바 있 다. 예를 들어, 격조사가 포함된 '아빠한테’라는 말을 들었을 때 뒤 이을 동사의 대상이 누구인지 아동은 더 쉽게 이해할 수 있을 것이 다. 마찬가지로 '인형한테 사과랑 키위를 주자'라는 문장을 들은 아 동이 ‘키위'라는 단어에 익숙하지 않더라도 '랑'이라는 접속조사 를 이해한다면 사과와 같은 범주의 사물임을 이해하는데 도움이 될 것이다. 이러한 결과는 아동의 문법발달에 관한 설명에 있어서 생득적이고 내재된 문법적 역량(grammatical competence)을 가정 하는 생성주의적 접근을 지지할 수도, 경험을 통한 문법지식의 형 성을 옹호하는 구성주의적 접근을 지지할 수도 있다. 그리고 해당 주제와 관련한 다양한 중재 방식의 효과를 탐색하는 후속연구가 지속적으로 진행되어야 할 필요성을 보여준다.

본 연구를 수행하고 결과를 분석함에 있어서 나타난 제한점과 후속연구에 대한 제언은 다음과 같다.
첫째, 유사한 언어 자극을 제시하기 위해 이 연구에서는 스크립 트 활동을 적용하였다. 그러나 앞선 경험의 이월효과(carryover ef$\mathrm{fect}$ 를 완전히 통제하지 못하여 TI 조건에서도 기능어 사용의 빈 도가 점차 증가하는 양상을 보였다. 또한 자유놀이의 특성 상 성인 이 목표 기능어를 제시하는 빈도와 비율을 완전히 통제하기 어려 웠다. 후속연구에서는 기능어 자극과 반응을 적절히 통제할 수 있 는 중재 맥락을 구성하여 진행할 필요가 있다.

둘째, 대상 아동이 기존에 습득하고 사용한 다양한 조사와 연결 어미를 파악하고 통제할 필요가 있었다. 본 연구는 조사와 연결어 미의 비율로 측정하였기에 아동이 동일한 문법형태소를 반복적으 로 사용하는 경우 높은 비율이라는 착시효과가 나타날 수밖에 없 다. 따라서 추후에 진행되는 연구는 소수의 문법형태소에 초점을 맞추거나, 조사와 연결어미별 분석을 구체적으로 진행하여야 할 것 이다.

마지막으로, 추후 대상 아동의 충분한 수만이 아니라 다양한 장 애군을 대상으로 종단적인 후속연구가 진행된다면 평가 및 중재를 위해 유용한 방향과 근거를 제시할 수 있을 것이라 사료되었다.

\section{REFERENCES}

Aslin, R. N., \& Newport, E. L. (2012). Statistical learning: from acquiring specific items to forming general rules. Current Directions in Psychological Science, 21(3), 170-176.

Bain, B. A., \& Olswang, L. B. (1995). Examining readiness for learning twoword utterances by children with specific expressive language impairment. American Journal of Speech-Language Pathology, 4(1), 81-91.

Bredin-Oja, S. L., \& Fey, M. E. (2014). Children's responses to telegraphic and grammatically complete prompts to imitate. American Journal of SpeechLanguage Pathology, 23(1), 15-26.

Brown, R. (1973). A first language, the early stages. Cambridge, MA: Harvard University Press.

Chang-Song, Y. K, Lee, G., Kwak, K., \& Sung, H. (2003). Relations of maternal inputs to lexical development of Korean infants. Korean Journal of Psychology, 16(4), 227-241.

Chang-Song, Y. K., Lim, H. J., \& Kwak, K. (2004). The effects of lexical category of maternal linguistic inputs on early lexical development of Korean infants. Korean Journal of Psychology, 23(2), 105-120.

Chung, B. (2013). Connective endings of 2 to 5 year old typically developing children. The Korean Journal of Early Childhood Special Education, 13(4), 233-246. 
Eyer, J. A., Leonard, L. B., Bedore, L. M., McGregor, K. K., Anderson, B., \& Viescas, R. (2002). Fast mapping of verbs by children with specific language impairment. Clinical Linguistics \& Phonietics, 16(1), 59-77.

Fernald, A., \& Hurtado, N. (2006). Names in frames: infants interpret words in sentence frames faster than words in isolation. Developmental Science, 9(3), F33-F40.

Fernald, A., Taeschner, T., Dunn, J., \& Papousek, M., de Boysson-Bardies, B., \& Fukui, I. (1989). A cross-language study of prosodic modifications in mothers' and fathers' speech to preverbal infants. Journal of Child Language, 16(3), 477-501.

Grieser, D. L., \& Kuhl, P. K. (1988). Maternal speech to infants in a tonal language: support for universal prosodic features in motherese. Developmental Psychology, 24(1), 14-20.

Hoff, E. (2014). Language development. Belmont, CA: Cengage Learning. Hwang, M. (2003). The production of grammatical morphemes of Korean children with developmental language impairments. Speech Sciences, 10(3), 47-64.

Kim, M. (2016). A study on the validity of measurement of MLU in proficiency evaluation of Korean. Korean Education, 109, 453-484.

Kim, Y. T. (2014). Diagnosis and treatment of childhood language disorders. Seoul: Hakjisa.

Kim, Y. T., \& Lombardino, L. J. (1991). The efficacy of script contexts in language comprehension intervention with children who have mental retardation. Journal of Speech, Language, and Hearing Research, 34(4), 845-857.

Kim, Y. T., Seong, T. J., \& Lee, Y. (2003). Preschool receptive-expressive language Scale (PRES). Seoul: Seoul Community Rehabilitation Center.

Kwon, D. H., \& Lee, E. K. (1999). A study on the development of case morphemes in normal children aged from two to four years who live in Taegu. Journal of Speech-Language \& Hearing Disorders, 8(2), 131-153.

Kwon, D. H., \& Jung, B. (1999). A study of development of complex sentences in the normal children aged from 2 to 5 years. Journal of Speech-Language \& Hearing Disorders, 8(1), 157-173.

Lee, H. R., Chang-Song, Y., Choi, Y. L., \& Lee, S. (2008). Acquisition of grammatical function words in Korean Children. Korean Journal of Communication Disorders, 13(2), 159-173.

Lee, S. H., Park, E. H., \& Kim, Y. T. (2000). Single subject research in educational and clinical settings. Seoul: Hakjisa.

Lew-William, C., Pelucchi, B., \& Saffran, J. R. (2011). Isolated words enhance statistical language learning in infancy. Developmental Science, 14(6), 13231329.
Liu, H. M., Kuhl, P. K., \& Tsao, F. M. (2003). An association between mother's speech clarity and infants' speech discrimination skills. Applied Psychology: An international Review, 6(3), F1-F10.

Lorang, E., Venker, C. E., \& Sterling, A. (2020). An investigation into maternal use of telegraphic input to children with Down syndrome. Journal of Child Language, 47(1), 225-249.

Pae, S. (1997). A study of acquisition in grammatical morphemes of Korean children. Korean Journal of Communication \& Disorders, 2, 27-42.

Shin, M. S., \& Cho, S. C. (2012). Korean-Leiter International Performance Scale-Revised. Seoul: Hakjisa.

Song, H. (2016). The influence of maternal utterance-facilitation behaviors on infants' nonverbal expression, onomatopoeia and lexical development. The Korean Journal of Developmental Psychology, 29(3), 1-16.

Tomasello, M., \& Olguin, R. (1993). Twenty-three-month-old children have a grammatical category of noun. Cognitive Development, 8(4), 451-464.

Trainor, L. J., \& Desjardins, R. N. (2002). Pitch characteristics of infant-directed speech affect infants' ability to discriminate vowels. Psychonomic Bulletin \& Review, 9(2), 335-340.

Van Kleeck, A., Schwarz, A. L., Fey, M., Kaiser, A., Miller, J., \& Weitzman, E. (2010). Should we use telegraphic or grammatical input in the early stages of language development with children who have language impairment? a meta-analysis of the research and expert opinion. American Journal of Speech-Language Pathology, 19(1), 3-21.

Venker, C. E., Bolt, D. M., Meyer, A., Sindberg, H., Weismer, S. E., \& TagerFlusberg, H. (2015). Parent telegraphic speech use and spoken language in preschoolers with ASD. Journal of Speech, Language, and Hearing Research, 58(6), 1733-1746.

Venker, C. E., \& Stronach, S. T. (2017). When is simplified too simple? emerging research points to benefits of using simple, grammatically correct sentences with children with delays. The ASHA Leader, 22(1), 42-47.

Venker, C. E., Yasick, M., \& McDaniel, J. (2019). Using telegraphic input with children with language delays: a survey of speech-language pathologists' practices and perspectives. American Journal of Speech-Language Pathology, 28(2), 676-696.

Weizman, Z. O., \& Snow, C. E. (2001). Lexical output as related to children's vocabulary acquisition: effects of sophisticated exposure and support for meaning. Developmental Psychology, 37(2), 265-279.

Yi, S. H. (2000). The acquisition of Korean grammatical morphemes in early childhood. Korean Journal of Child Studies, 21(4), 51-68. 
Appendix 1. 중재활동에서 사용한 스크립트의 종류와 도구

\begin{tabular}{lll}
\hline \multicolumn{2}{c}{ 스크립트 } \\
\hline 1 & 미술 놀이 & 기차모형, 크레파스, 색연필, 풀, 테이프 등 \\
2 & 옷 입고 놀이터 가기 & 가족인형, 의류모형, 놀이터 교구 등 \\
3 & 마트 놀이 & 인형, 사물카드, 사물모형, 계산기 모형, 카트, 봉지 등 \\
\hline
\end{tabular}

Appendix 2. 중재활동에서 사용한 스크립트의 순서 및 구어자극의 예

$\mathrm{Gl}$ 조건: 미술놀이(기차 만들기)

\begin{tabular}{llll}
\hline \multirow{2}{*}{ 활동순서 } & \multicolumn{2}{c}{ 구어자극 } & \multicolumn{2}{c}{ 긍어 } \\
\cline { 3 - 4 } & & 조사 & 연결어미 \\
\hline 활동 소개 & 선생님이 재미있는 걸 가져왔어요 & 를(2) & \\
& (ST) 기차(를) 꺼내요. & & \\
& (ST) 기차(를) 만들 거예요. & & \\
활동 진행 & (ST) 기차(를) 색칠하(고) & 를(1) & 고(1) \\
& (ST) 기차(에) 붙여요. & 에(1) & 면(1) \\
& (PT) 이(도) 색칠해요. & 도(1) & \\
& (PT) 가위(로) 자르(면) & 로(1) & 고(1) \\
활동 마무리 & (PT) 이이(도) 만들었어요 & 도(3) & \\
& (ST) 뽀로로가 타(고), 포비(도) 타고 & & \\
& (ST) 엄마(도) 보여줘요. & & \\
\hline
\end{tabular}

$\mathrm{ST}=$ 혼잣말 기법(self-talk); $\mathrm{PT}=$ 평행적 발화(parallel-talk). 


\section{국문초록}

\section{성인의 언어자극 유형이 언어발달지연아동의 기능어 학습에 미치는 효과}

정부자 $\cdot$ 김미리 ${ }^{2}$

'조선대학교 언어치료학과, 2준재활의학과의원

배경 및 목적: 전보식 문장이 언어발달과정에서 자연스럽게 나타나는 발화형식이긴 하나, 언어적 어려움을 보이는 아동에게 제공하는 언어자극의 형식으로 적합한가에 관한 논의는 꾸준히 제기되었다. 따라서 본 연구는 3 세에서 4 세 언어발달지연아동을 대상으로 전보식 및 문법완성식의 두 가지 언어촉진방법이 조사 및 연결어미라는 기능어 표현에 유의한 차별적 영향을 미치는지 탐색하고자 하였다. 방 법: 4 명의 아동을 대상으로 6 개의 조사와 4 개의 연결어미를 제공하는 문법완성식 언어촉진활동조건과 기능어가 생략된 내용어 중심의 전보식 문장을 제공하는 언어촉진활동 조건의 두 가지를 다양한 스크립트 활동 속에서 진행하였다. 두 조건에서 나타나는 기능어의 산 출비율을 비교하기위해 교대중재설계(alternating treatment design, ATD)를 적용하였다. 결과: 전보식 문장을 제공한 조건에 비해 문법 적으로 완전한 문장으로 조사와 연결어미를 제공한 조건에서 전반적으로 높은 표현이 비율이 보인 것으로 확인되었다. 연결어미의 경우 조사에 비해 두 조건 간의 차이가 적은 것으로 분석되었다. 논의 및 결론: 아동에 따라 조사와 연결어미 표현의 비율에서 다른 추이를 보 였으며, 이는 아동들의 학습잠재력이라는 측면에서 설명이 가능하였다. 종합적으로 언어촉진방식에 따라, 기능어의 종류에 따라, 그리 고 아동의 반응성에 따라 표현비유의 증감에 차이를 보였다. 또한 다양한 중재방식의 효과를 탐색하는 후속연구를 제언하였다.

핵심어: 전보식 언어촉진, 문법완성식 언어촉진, 스크립트, 언어발달지연

\section{참고문헌}

권도하, 이은경(1999). 2-4세 유아의 격조사 발달에 관한 연구. 언어치료연구, 8(2), 131-153.

권도하, 정분선(1999). 2-4세 유아의 복문 발달에 관한 연구. 언어치료연구, 8(1), 17-173.

김명광(2016). 언어숙달도 평가에서 MLU 측정법의 해석 타당성에 대한 일고. 새국어교육, 109, 453-484.

김영태(2014). 아동언어장애의 진단 및 치료. 서울: 학지사.

김영태, 성태제, 이윤경(2003). 취학 전 아동의 수용언어 및 표현언어 발달척도. 서울: 서울장애인종합복지관.

배소영(1997). 한국아동의 문법형태소 습득에 관한 연구: 조사 '가, 이, 는, 도, 를' 언어청각장애연구, 2, 27-42.

신민섭, 조수철(2012). 한국판 라이터 비언어성 지능검사. 서울: 학지사.

이소현, 박은혜, 김영태(2000). 교육 및 임상현장 적용을 위한 단일대상연구. 서울: 학지사

이순형(2000). 한국아동이 초기에 획득한 문법적 형태소의 종류 및 획득 시기. 아동학회지, 21(4), 51-68.

이희란, 장유경, 최유리, 이승복(2008). 부모보고를 통해 종단관찰한 한국 아동의 초기 문법 형태소 습득. 언어청각장애연구, 13(2), 159-173.

송하나(2016). 어머니의 발화 촉진 행동이 영아의 의사표현몸짓, 의성어, 어휘 발달에 미치는 영향. 한국심리학회지: 발달, 29(3), 1-16.

장유경, 이근영, 곽금주, 성현란(2003). 어머니의 언어적 입력이 영아의 초기 어휘발달에 미치는 영향 한국심리학회지: 발달, 16(4), 227-241.

장유경, 임현정, 곽금주(2004). 언어적 입력의 품사가 영아의 초기 어휘발달에 미치는 영향. 한국심리학회지: 일반, 23(2), 105-120.

정부자(2013).2세에서 5세 일반아동의 자발화에 나타난 연결어미 발달 특성. 유아특수교육연구, 13(4), 233-246.

황민아(2003). 언어발달장애아동의 문법형태소 산출. 음성과학, 10(3), 47-64.

\section{ORCID}

정부자(제1저자, 교신저자, 교수 https://orcid.org/0000-0002-6158-6637); 김미리(공동저자, 언어재활사 https://orcid.org/0000-0003-2496-4341) 